\title{
The potential contribution of increased vegetable and fruit consumption to health gain in the European Union
}

\author{
Michael Joffe ${ }^{1, *}$ and Aileen Robertson ${ }^{2}$ \\ 'Department of Epidemiology \& Public Health, Imperial College School of Medicine, St Mary's Campus, \\ Norfolk Place, London W2 1PG, UK: ${ }^{2}$ Acting Regional Adviser for Nutrition, WHO Regional Office for Europe, \\ Copenhagen, Denmark
}

Submitted 27 October 2000: Accepted 9 January 2001

\begin{abstract}
Background: The risk of many important diseases can be reduced by consuming a diet rich in vegetables and fruit. For this reason the World Health Organization (WHO) recommends a daily intake of more than $400 \mathrm{~g}_{\text {person }}{ }^{-1}$. The pattern of both the supply and intake of vegetables and fruit and the potential health gain achieved by increasing intake in the European Union (EU) and three accession countries are presented in this paper.

Methods: Patterns of supply and dietary intake were assessed using (1) FAO food balance sheets, which allow comparison between the levels of supply in countries but do not reflect actual intake; and (2) survey data reflecting dietary intake. Using WHO mortality data for coronary heart and cerebrovascular disease and major cancers up to age 65 years, the number of preventable deaths is estimated, assuming vegetable and fruit consumption were levelled up to that of the highest consuming group, and assuming relative risks of $0.5,0.7$ or 0.9 .

Results: Vegetable and fruit consumption varies considerably between EU Member States. The populations of about half (seven) of the EU Member States have a mean daily intake of less than $275 \mathrm{~g}$. Using the best current estimates of relative risk, over 26,000 deaths before the age of 65 years would be prevented annually in the EU if intake was levelled up to the highest consumption levels (and about double this number of deaths before the age of 75 years).

Conclusion: Increasing the intake of vegetables and fruit is feasible and could result in considerable improvements in public health within the EU. Priority should be given to developing methods that demonstrate the burden of disease caused by too low intakes of vegetables and fruit. This would enable the appropriate social, cultural and economic policies to be developed within the EU.
\end{abstract}

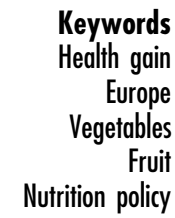

A diet rich in vegetables and fruits and low in saturated fats is protective against a large number of non-communicable diseases, such as cardiovascular diseases and certain cancers $^{1-3}$. These diseases are the most important causes of premature death in countries of the European Union (EU). Biochemical studies have demonstrated the links between the nutrient and non-nutrient constituents of vegetables and fruit and related protective physiological pathways.

The World Health Organization (WHO) recommends a daily intake of more than $400 \mathrm{~g}$ of vegetables and fruit per person ${ }^{4}$. A large number of studies have confirmed that such a diet is associated with reduced all-cause mortality $^{5-7}$ as well as reduced mortality from cardiovascular diseases and cancer.
Reviews of the cancer literature provide convincing evidence that vegetable and fruit consumption is protective against certain common cancers ${ }^{8-10}$. The risk of gastric carcinoma is reduced among those who consume higher amounts of vegetables and fruit, the relative risk estimates tending to be approximately 0.7 , with a fairly consistent dose-response relationship9. Oesophageal cancer is also inversely related to fruit and vegetable consumption, although the existing evidence may not be directly applicable to Europe ${ }^{9}$. The incidence of colorectal cancer is lower among higher consumers of vegetables and of fibre, with relative risk estimates generally between 0.9 and $0.5^{9}$. Breast cancer risk may be inversely related with the intake of vegetables (especially yellow/green vegetables), with relative risks 
of 0.83 and 0.86 in two cohort studies 9 . A lower risk of carcinoma of the lung is associated with the intake of vegetables and especially of fruit, with typical relative risk estimates in the region of $0.7^{9}$.

Reviews of the relationship between ischaemic heart disease (IHD) and vegetable and fruit intake suggest a moderate protective effect ${ }^{10-12}$. One estimate of the relative risk is 0.85 , comparing the 90th with the 10th centile of consumption ${ }^{12}$. Possible mechanisms include higher intakes of anti-oxidants, potassium, folate and fibre $^{12,13}$. Dietary fibre has been shown to reduce the risk of death from coronary heart disease by $31 \%$ in a randomised controlled trial ${ }^{14}$, and was associated with a $55 \%$ reduction in a cohort study ${ }^{15}$. In both studies, cereal fibre was more protective than that from fruit or vegetables, emphasising the health importance of a wide range of foods of plant origin. The protective effect of vegetables and fruit extends to stroke ${ }^{11}$, and an inverse association has also been noted between nuts and IHD $^{16}$.

The association between a vegetarian diet and mortality from IHD has been established by a collaborative analysis of five prospective studies ${ }^{17}$. The principal finding was that vegetarians had a mortality rate that was $76 \%$ of that of non-vegetarians - 55\% among those under 65 years after adjustment for age, sex and smoking.

A randomised controlled trial found that dietary intervention achieved a strong protective effect. A 'Cretan' Mediterranean diet, given to men in Lyon who had survived a myocardial infarction, was well adhered to by participants $^{18}$. It included higher intakes of vegetables, legumes, fruit and bread, and more fish, as well as substitution of types of fat and of types of meat (chicken for red meat). Results so far indicate that this total package, which goes considerably further than just increasing the vegetable and fruit intake, was associated with a fall in total mortality, in cardiac deaths and in incident cancers, all relative risks being in the range 0.35 to $0.44^{18}$.

This paper has two purposes: first, to describe both the supply and intake levels of vegetable and fruit within the EU and three accession countries; and second, to estimate the potential health gain if vegetable and fruit intake were to increase substantially. As the dietary intake data available are insufficient to estimate the effect of an increase to the WHO recommended level, the impact of levelling up low intakes to the highest reported consumption levels is estimated.

The potential health gain is estimated by the number of premature deaths that could be prevented each year among those aged up to 65 years. Morbidity is not considered, as the data are not available, but the suffering, health care costs and total burden of disease implied by each death are immense. Until the necessary epidemiological data are available, estimates of potential health gain need to be based on premature mortality data and preventable deaths. These estimates can be revised as new evidence accumulates to provide better estimates of relative risk.

\section{Methods}

\section{Sources of dietary data}

Some EU Member States carry out surveys to assess dietary intake, including individual daily consumption of vegetables and fruit. However, national surveillance systems vary enormously in the different Member States. Some countries do not assess dietary intake, and where this is done, different methods are used to collect the data. Therefore current methods of assessing dietary intake are inadequate to allow good comparisons between the EU countries $^{19}$. Most of the intake data cited in this paper were supplied by the national governmental nutrition counterparts to the WHO Regional Office for Europe. However, because not all countries have nationally representative dietary intake surveys, other data sources, from non-nationally representative surveys or data from the DAFNE study, which is derived from household budget surveys ${ }^{20}$, have been used to estimate the mean national intakes of vegetables and fruit.

A major problem with comparing the intake figures from the different EU countries is that the intake data relate to different years, ranging from 1980 in Portugal to 1998 in Austria.

In contrast to the intake data, EU-wide comparisons can be made using the United Nations Food and Agriculture Organisation (FAO) food balance sheet data. They provide an estimate of the supply of vegetables and fruit available to the domestic market by:

1. adding the total quantities produced nationally and imported (adjusted for changes in stocks);

2. subtracting the quantities exported, fed to livestock, used in manufacture and lost during storage and transport; and

3. dividing this estimated national food supply by the population size to derive the per capita figure in $\mathrm{kg}$ per year with no breakdown of the distribution between genders or age groups.

The FAO figures only provide an estimate of the quantity of food available for human consumption. A substantial proportion of the available vegetables and fruit is destroyed or wasted and not consumed. By subtracting the existing intake data from the FAO supply data for each country, an estimate of the proportion of vegetables and fruit not consumed in each country can be calculated.

\section{Potential bealth gain: statistical metbods}

Epidemiological studies of dietary intake generally present their findings in terms of the change in risk of death or disease when comparing equal divisions (quantiles) of the population, e.g. tertiles or quintiles, corresponding to different levels of consumption. The ideal way of drawing 
conclusions from this literature would be to construct a dose-response curve by plotting all component pieces of evidence on a single diagram. This would allow the distinction to be made between studies on populations with differing levels of consumption, which could be important if the dose-response relationship is far from linear.

Unfortunately, the data on actual intakes within each category are not consistently reported in the epidemiological literature. For example, some papers give the consumption of vegetables and fruit by each quantile in terms of the number of portions per $\mathrm{day}^{21}$, week ${ }^{22}$ or month ${ }^{23}$; others give values in grams for the median and/ or mean and standard deviation ${ }^{24}$; while many give no information at all on consumption levels ${ }^{25,26}$. Among those studies for which information is available, the intake levels vary substantially. Therefore for the estimations carried out here it was decided to calculate the effect of levelling up the intake of the whole population to equal that of the highest consumers.

There are additional questions to consider in interpreting the observed relative risks, in addition to the considerations of data quality, selection effects and statistical power that are common to all epidemiological studies. One is the dispersion of consumption levels within the population: if there were no variation in intake, it would be impossible to demonstrate an association with disease rates. A second is the choice of the number of quantiles, as with smaller divisions the extremes are more widely separated and can therefore be expected to have a relative risk that is further from unity.

The method of calculation used in this paper quantifies the fall in the annual number of premature deaths that would result if the intake among all the lower quantiles were increased to equal that of the highest quantile. It assumes a similar relative risk and range of consumption in the EU Member States as in the populations where the research was done, or alternatively, a linear no-threshold dose-response relationship.

The proportion of deaths saved depends on the relative risk (RR) or death rate ratio, and was calculated using the formula for the Population Attributable Risk Proportion (see Appendix), applied to deaths rather than to incident cases (assuming therefore the same RR):

$$
(1-\mathrm{RR}) /(1+\mathrm{RR}) \text {. }
$$

The annual number of deaths saved was then obtained by multiplying the existing total number of annual deaths by this proportion. The disease-specific mortality figures occurring up to age 65 years, for each EU Member State and the three largest accession countries, were obtained from World Health Statistics, published annually by $\mathrm{WHO}^{27,28}$. Estimates were calculated based on three different levels of relative risk of the highest consuming group compared with the lowest, 0.5, 0.7 and 0.9, in the manner of a sensitivity analysis.
While unsophisticated in its assumption of levelling up low consumption to that of the group with the highest level, this method can provide an estimate of the potential health gain. Moreover, it allows re-interpretation of the data as further epidemiological evidence continues to accumulate.

\section{Results}

\section{Dietary intake}

The FAO figures show that the availability of vegetables and fruits varies greatly between EU Member States, from only $358 \mathrm{~g}$ per capita per day in Ireland to $1122 \mathrm{~g}$ in Greece (Table 1). This trend is mirrored in the intake data, with more vegetables and fruit being consumed in southern compared with northern Europe. Subtracting the intake figures from the FAO figures, it can be estimated that the average percentage of vegetables and fruits available but not consumed in the EU is around $30 \%$. Moreover, according to the intake data, the mean consumption in about half (seven) of the Member States is less than $275 \mathrm{~g}$ of vegetables and fruit per person per day.

However, mean consumption of vegetable and fruit is a poor measure of the intake distribution within a population. Vegetable and fruit intake is not normally distributed but is highly skewed to the right ${ }^{20}$. Thus, both the FAO and mean intake values conceal the large proportion of the population within each country with low consumption levels of vegetables and fruit.

Table 1 Availability and intake of vegetables/fruit in the EU Member States

\begin{tabular}{lcc}
\hline & $\begin{array}{c}\text { Availability } \\
\text { (FAO data, 1995) } \\
\left(\text { g person }^{-1} \text { day }^{-1}\right)\end{array}$ & $\begin{array}{c}\text { Intake } \\
\left.\text { (g person }^{-1} \text { day }^{-1}\right)\end{array}$ \\
\hline UK & 461 & $208(1995)$ \\
Ireland & 358 & $215(1989)$ \\
Austria & 576 & $235(1998)$ \\
Netherlands & 636 & $242(1992)$ \\
Germany & 514 & $250(1990)$ \\
Sweden & 418 & $265(1989)$ \\
Denmark & 415 & $273(1995)$ \\
Belgium/Luxemburg & 661 & $360(1982)$ \\
Portugal & 725 & $399(1980)$ \\
Finland* & 413 & $433(1992)^{37}$ \\
France & 619 & $437(1996)$ \\
Italy & 755 & $480(1995)$ \\
Greece & 1122 & $511(1995)$ \\
Spain & 659 & $604(1994)^{29}$ \\
Czech & 418 & $250 \dagger$ \\
Poland & 461 & $302(1997)^{20}$ \\
Hungary & 368 & $360(1997)^{20}$ \\
\hline
\end{tabular}

* For Finland, the FAO availability data are from 1995 and do not include home produce, and intake data are from 1992 and refer to adults aged 24 to 65 years of age, whereas the FAO availability data cover the whole population including young and the old, who may consume less vegetables and fruit.

† Czech Republic: personal communication - not national data. 
Table 2 Deaths (of people aged 15-64) from major diseases in the Member States and in the EU, and estimates of the number of deaths potentially preventable assuming different levels of relative risk

\begin{tabular}{|c|c|c|c|c|}
\hline & Number of deaths year ${ }^{-1}$ & $D_{0.5^{*}}$ & $D_{0.7^{*}}$ & $D_{0.9}{ }^{*}$ \\
\hline \multicolumn{5}{|l|}{ UK 1995} \\
\hline Ischaemic heart disease & 21,941 & 7314 & 3872 & 1155 \\
\hline Cerebrovascular disease & 5393 & 1798 & 952 & 284 \\
\hline Cancer of oesophagus \& stomach & 3123 & 1041 & 551 & 164 \\
\hline Colo-rectal cancer & 3757 & 1252 & 663 & 198 \\
\hline Cancer of bronchus/lung & 8354 & 2785 & 1474 & 400 \\
\hline Breast cancer & 5362 & 1787 & 946 & 282 \\
\hline \multicolumn{5}{|l|}{ Ireland 1993} \\
\hline Ischaemic heart disease & 1382 & 461 & 244 & 73 \\
\hline Cerebrovascular disease & 277 & 92 & 49 & 15 \\
\hline Cancer of oesophagus \& stomach & 161 & 54 & 28 & 8 \\
\hline Colo-rectal cancer & 198 & 66 & 35 & 10 \\
\hline Cancer of bronchus/lung & 410 & 137 & 72 & 22 \\
\hline Breast cancer & 283 & 94 & 50 & 15 \\
\hline \multicolumn{5}{|l|}{ Austria 1995} \\
\hline Ischaemic heart disease & 2308 & 769 & 407 & 121 \\
\hline Cerebrovascular disease & 788 & 263 & 139 & 41 \\
\hline Cancer of oesophagus \& stomach & 413 & 138 & 73 & 22 \\
\hline Colo-rectal cancer & 552 & 184 & 97 & 29 \\
\hline Cancer of bronchus/lung & 1074 & 358 & 190 & 57 \\
\hline Breast cancer & 649 & 216 & 115 & 34 \\
\hline \multicolumn{5}{|l|}{ Netherlands 1995} \\
\hline Ischaemic heart disease & 3455 & 1152 & 610 & 182 \\
\hline Cerebrovascular disease & 1112 & 371 & 196 & 59 \\
\hline Cancer of oesophagus \& stomach & 750 & 250 & 132 & 39 \\
\hline Colo-rectal cancer & 974 & 325 & 172 & 51 \\
\hline Cancer of bronchus/lung & 2609 & 870 & 460 & 137 \\
\hline Breast cancer & 1384 & 461 & 244 & 73 \\
\hline \multicolumn{5}{|l|}{ Germany 1995} \\
\hline Ischaemic heart disease & 25,439 & 8480 & 4489 & 1339 \\
\hline Cerebrovascular disease & 8051 & 2684 & 1421 & 424 \\
\hline Cancer of oesophagus \& stomach & 5610 & 1870 & 990 & 295 \\
\hline Colo-rectal cancer & 6664 & 2221 & 1176 & 351 \\
\hline Cancer of bronchus/lung & 13,751 & 4584 & 2427 & 724 \\
\hline Breast cancer & 7437 & 2479 & 1312 & 391 \\
\hline \multicolumn{5}{|l|}{ Sweden 1995} \\
\hline Ischaemic heart disease & 2226 & 742 & 393 & 117 \\
\hline Cerebrovascular disease & 569 & 190 & 100 & 30 \\
\hline Cancer of oesophagus \& stomach & 241 & 80 & 43 & 13 \\
\hline Colo-rectal cancer & 439 & 146 & 77 & 23 \\
\hline Cancer of bronchus/lung & 826 & 275 & 146 & 43 \\
\hline Breast cancer & 556 & 185 & 98 & 29 \\
\hline \multicolumn{5}{|l|}{ Denmark 1993} \\
\hline Ischaemic heart disease & 1646 & 549 & 290 & 87 \\
\hline Cerebrovascular disease & 508 & 169 & 90 & 27 \\
\hline Cancer of oesophagus \& stomach & 223 & 74 & 39 & 12 \\
\hline Colo-rectal cancer & 413 & 138 & 73 & 22 \\
\hline Cancer of bronchus/lung & 1012 & 338 & 179 & 53 \\
\hline Breast cancer & 499 & 166 & 88 & 26 \\
\hline \multicolumn{5}{|l|}{ Belgium 1992/Luxemburg 1995} \\
\hline Ischaemic heart disease & 2086 & 695 & 368 & 110 \\
\hline Cerebrovascular disease & 918 & 306 & 162 & 48 \\
\hline Cancer of oesophagus \& stomach & 467 & 156 & 82 & 25 \\
\hline Colo-rectal cancer & 665 & 222 & 117 & 35 \\
\hline Cancer of bronchus/lung & 2196 & 732 & 388 & 116 \\
\hline Breast cancer & 1008 & 336 & 178 & 53 \\
\hline \multicolumn{5}{|l|}{ Portugal 1995} \\
\hline Ischaemic heart disease & 1775 & 592 & 313 & 93 \\
\hline Cerebrovascular disease & 1894 & 631 & 334 & 100 \\
\hline Cancer of oesophagus \& stomach & 988 & 329 & 174 & 52 \\
\hline Colo-rectal cancer & 628 & 209 & 111 & 33 \\
\hline Cancer of bronchus/lung & 973 & 324 & 172 & 51 \\
\hline Breast cancer & 692 & 231 & 122 & 36 \\
\hline
\end{tabular}


Table 2. continued

\begin{tabular}{|c|c|c|c|c|}
\hline & Number of deaths year ${ }^{-1}$ & $D_{0.5^{*}}$ & $D_{0.7^{*}}$ & $D_{0.9}{ }^{*}$ \\
\hline \multicolumn{5}{|l|}{ Finland 1995} \\
\hline Ischaemic heart disease & 1901 & 634 & 335 & 100 \\
\hline Cerebrovascular disease & 625 & 208 & 110 & 33 \\
\hline Cancer of oesophagus \& stomach & 224 & 75 & 40 & 12 \\
\hline Colo-rectal cancer & 222 & 74 & 39 & 12 \\
\hline Cancer of bronchus/lung & 522 & 174 & 92 & 27 \\
\hline Breast cancer & 369 & 123 & 65 & 19 \\
\hline \multicolumn{5}{|l|}{ France 1994} \\
\hline Ischaemic heart disease & 6430 & 2143 & 1135 & 338 \\
\hline Cerebrovascular disease & 3685 & 1228 & 650 & 194 \\
\hline Cancer of oesophagus \& stomach & 3169 & 1056 & 559 & 167 \\
\hline Colo-rectal cancer & 3019 & 1006 & 533 & 159 \\
\hline Cancer of bronchus/lung & 8954 & 2985 & 1580 & 471 \\
\hline Breast cancer & 4193 & 1398 & 740 & 221 \\
\hline \multicolumn{5}{|l|}{ Italy 1993} \\
\hline Ischaemic heart disease & 11,536 & 3845 & 2038 & 607 \\
\hline Cerebrovascular disease & 5425 & 1808 & 957 & 286 \\
\hline Cancer of oesophagus \& stomach & 3751 & 1250 & 662 & 197 \\
\hline Colo-rectal cancer & 3648 & 1216 & 644 & 192 \\
\hline Cancer of bronchus/lung & 10,302 & 3434 & 1818 & 542 \\
\hline Breast cancer & 4880 & 1627 & 861 & 257 \\
\hline \multicolumn{5}{|l|}{ Greece 1995} \\
\hline Ischaemic heart disease & 2928 & 976 & 517 & 154 \\
\hline Cerebrovascular disease & 1332 & 444 & 235 & 70 \\
\hline Cancer of oesophagus \& stomach & 389 & 130 & 69 & 20 \\
\hline Colo-rectal cancer & 335 & 112 & 59 & 18 \\
\hline Cancer of bronchus/lung & 1770 & 590 & 312 & 93 \\
\hline Breast cancer & 679 & 226 & 120 & 36 \\
\hline \multicolumn{5}{|l|}{ Spain 1994} \\
\hline Ischaemic heart disease & 6246 & 2082 & 1102 & 329 \\
\hline Cerebrovascular disease & 3231 & 1077 & 570 & 170 \\
\hline Cancer of oesophagus \& stomach & 2592 & 864 & 457 & 136 \\
\hline Colo-rectal cancer & 2281 & 760 & 403 & 120 \\
\hline Cancer of bronchus/lung & 5649 & 1883 & 997 & 297 \\
\hline Breast cancer & 2729 & 910 & 482 & 144 \\
\hline \multicolumn{5}{|l|}{ All EU Member States } \\
\hline Ischaemic heart disease & 91,299 & 30,433 & 16,112 & 4805 \\
\hline Cerebrovascular disease & 33,808 & 11,269 & 5966 & 1779 \\
\hline Cancer of oesophagus \& stomach & 22,101 & 7367 & 3900 & 1163 \\
\hline Colo-rectal cancer & 23,795 & 7932 & 4199 & 1252 \\
\hline Cancer of bronchus/lung & 58,402 & 19,467 & 10,306 & 3074 \\
\hline Breast cancer & 30,720 & 10,240 & 5421 & 1617 \\
\hline \multicolumn{5}{|l|}{ Czech Republic 1993} \\
\hline Ischaemic heart disease & 5994 & 1998 & 1058 & 315 \\
\hline Cerebrovascular disease & 2094 & 698 & 370 & 110 \\
\hline Cancer of oesophagus \& stomach & 672 & 224 & 119 & 35 \\
\hline Colo-rectal cancer & 1219 & 406 & 215 & 64 \\
\hline Cancer of bronchus/lung & 2584 & 861 & 456 & 136 \\
\hline Breast cancer & 828 & 276 & 146 & 44 \\
\hline \multicolumn{5}{|l|}{ Poland 1995} \\
\hline Ischaemic heart disease & 15,483 & 5161 & 2732 & 815 \\
\hline Cerebrovascular disease & 6870 & 2290 & 1212 & 362 \\
\hline Cancer of oesophagus \& stomach & 2922 & 974 & 516 & 154 \\
\hline Colo-rectal cancer & 2379 & 793 & 420 & 125 \\
\hline Cancer of bronchus/lung & 9047 & 3016 & 1597 & 476 \\
\hline Breast cancer & 2460 & 820 & 434 & 129 \\
\hline \multicolumn{5}{|l|}{ Hungary 1995} \\
\hline Ischaemic heart disease & 7373 & 2458 & 1301 & 388 \\
\hline Cerebrovascular disease & 3719 & 1240 & 656 & 196 \\
\hline Cancer of oesophagus \& stomach & 1168 & 389 & 206 & 61 \\
\hline Colo-rectal cancer & 1246 & 415 & 220 & 66 \\
\hline Cancer of bronchus/lung & 3660 & 1220 & 646 & 193 \\
\hline Breast cancer & 979 & 326 & 173 & 52 \\
\hline
\end{tabular}

* For explanation, see text.

ICD-9 codes used were: ischaemic heart disease - 270 \& 279; cerebrovascular disease - 29; cancer of oesophagus \& stomach - 090 \& 091; colo-rectal cancer - 093 \& 094; cancer of bronchus/lung - 101; breast cancer - 113 . 


\section{Potential bealtb gain}

Table 2 gives the estimated number of deaths occurring annually for the age group 15 to 64 years in each country, and in the EU as a whole, for each disease. The last three columns give the number of deaths potentially prevented, assuming a causal relative risk of $0.5,0.7$ and $0.9\left(D_{0.5}\right.$, $D_{0.7}$ and $D_{0.9}$, respectively), by applying the above method to the country-disease-specific number of deaths. Any benefits from dietary change would occur after a lag of some years, which is specific to each disease.

For the EU as a whole, the overall estimate of numbers of deaths potentially preventable varies from 86,700 if a causal relative risk of 0.5 for each of the diseases is taken, to 45,900 and 13,700 assuming respectively 0.7 and 0.9 . The epidemiological evidence currently available suggests that the relative risks may be $0.7,0.7,0.7,0.9,0.9$ and 0.9 for oesophageal/stomach cancer, colo-rectal cancer, lung cancer, breast cancer, IHD and stroke, respectively. Using these figures (given in bold in the table), the potential health gain is over 26,000 deaths annually.

For the three candidate Member States, the numbers are greater (proportional to their population), owing to the higher mortality rates from these diseases.

\section{Discussion}

The data on both FAO food availability and dietary intake within the EU are subject to serious limitations. For example, the intake data, even if available, are based on different methods of collection (e.g. 24-hour recall, food records or household budget data) and in addition the data may not be based on nationally representative samples of the population. Moreover, the different years when the intake data were collected range from 1980 in Portugal to 1998 in Austria. In addition the years in which the two sets of data from FAO and intake surveys were collected are not the same. There may also be other problems, as is indicated by the data from Finland where the intake data appear to show that consumption is greater than the actual availability according to FAO statistics. This could be because (1) the data relate to different years (1995 and 1992); (2) the FAO data collected in Finland may not include home produce; and (3) the FAO statistics cover the whole population whereas the data from intake surveys refer only to adults aged 24 to 65 years. The intake and FAO statistics cited in this paper are therefore to be regarded as rough approximations until comparable data sets are available from improved dietary intake surveillance in the EU.

Despite these limitations, it is clear that a substantial proportion of the EU population is not consuming enough vegetables and fruit. In about half (seven) of the Member States, the mean recorded intake level is less than $70 \%$ of that recommended by WHO. Furthermore, even a country like Greece, which has a relatively high mean consumption (511 g), has a substantial proportion of the population (37\%) who fall below the recommended level ${ }^{20}$. In many EU Member States, there is a social gradient with lower intake among the less prosperous and/or less educated, for example in Spain ${ }^{29,30}$, the $\mathrm{UK}^{9}$ and in Finnish children ${ }^{31}$. The three selected accession countries from central Europe also appear to have mean intakes well below the WHO recommended $400 \mathrm{~g} \mathrm{person}^{-1} \mathrm{day}^{-1}$. There is evidence from former Socialist economies that low intake of fruits and vegetables is not only widespread but is responsible for a significant proportion of the health gap, contributing to the high mortality from non-communicable diseases ${ }^{32,33}$.

The effect of levelling up to the highest consuming group shows that the potential health gain could result in some tens of thousands of deaths saved each year under the age of 65 years. If the age group 65-74 were also included, the estimates would roughly be doubled. Moreover, there are no known adverse health effects associated with increasing vegetable and fruit intake.

The assumed scenario of behaviour change would involve a radical change in the shape of the distribution of consumption. Rose believed that distributions shift in position without changing their shape ${ }^{34}$, although there is no evidence for this. A more likely scenario is an upward shift in the whole distribution, with greater changes occurring at lower consumption levels where there is more scope for improvement. Whatever the exact nature of the change, the health gain could be achieved with a combination of both shifting and altering the shape of the distribution.

The analysis carried out in this paper could be more sophisticated in various ways. On the exposure side, the effect of raising consumption to a particular target, e.g. $400 \mathrm{~g}_{\text {person }}{ }^{-1} \mathrm{day}^{-1}$, could be estimated if valid dietary intake data were available from all Member States. In view of the potential that increasing vegetable and fruit intake has for reducing the burden of disease, it is highly desirable to improve nutritional surveillance and that the intake assessment methods are comparable. Data from such surveys could be used to quantify dietary intake more accurately, to identify low consumers and to monitor changes over time.

For the analysis of potential health gain, different outcome variables could be used in preference to the annual number of deaths saved. In EU countries, where life expectancy is already relatively high, the issue is not so much to add quantity to life but to add quality. The non-fatal consequences of disease may put an even greater burden on society than premature mortality. An indicator that combines mortality, morbidity and disability and measures the number of disability-adjusted life years (DALYs) ${ }^{35}$ has been developed. The DALY extends the concept of premature death to include equivalent years of 'healthy' life lost because of illness and disability. 
This method of analysis has been used in Sweden ${ }^{36}$ where it was suggested that $4.5 \%$ of DALYs are lost in EU countries due to poor nutrition, with an additional $3.7 \%$ and $1.4 \%$ due to obesity and physical inactivity. The Swedish analysis is not as detailed as the Global Burden of Disease analysis ${ }^{35}$ and is only for the EU. However, the Swedish study is one of the first to investigate the potential burden of disease coming from dietary risk factors. These were not included in the Global Burden of Disease report (GBD) published in $1996^{35}$. It is hoped that, by expanding the concepts of this paper, dietary risk factors and how they contribute to the global burden of disease will be included in the next GBD analysis, which will be published in 2001 .

The Finnish authorities ${ }^{37}$ demonstrate that a significant increase in mean vegetable and fruit intake is achievable over a reasonable time span. However, improved mean intake can mask a highly skewed distribution within a population. Before the appropriate public health policies can be implemented, it is crucial that the intake of vegetables and fruits is measured using valid methodologies. More attention should be focused on assessing the vegetable and fruit intake of vulnerable groups, notably low-income households, children and the EU accession countries.

A range of policies could be used to increase vegetable and fruit intake. Health education may be less important than lowering the price and improving the availability of vegetables and fruit. People on a low income tend to spend relatively more of it on food, and their first priority is to satisfy their energy needs. This means that there may very little money left for low-energy, but micronutrientrich, and relatively expensive vegetables and fruits. Poor people also tend to have fewer transport options and may find it difficult to get to shops if they are not within walking distance. In many countries low-income groups are the people most in need of increasing their vegetable and fruit intake. Fiscal policies should therefore be considered to help these disadvantaged groups have easier access ${ }^{38}$. As agricultural products already receive subsidies, it would make sense to modulate these in accordance with the scientific evidence on health benefits.

Attempts to reduce social inequalities and food poverty are desirable and could be achieved using special measures to support low-income groups who are foodinsecure. Measures could include: provision of small plots of land for the unemployed or ethnic minorities, including in large cities, to allow them to grow their own vegetables; protecting farmers' markets where local growers can sell their produce; community-supported agriculture schemes; co-operative bulk-buying initiatives within communities; and free or discounted school fruit. Some of these initiatives are discussed in more detail in the Urban Food and Nutrition Action Plan produced by the nutrition programme at the European Regional Office of $\mathrm{WHO}^{39}$.

\section{Acknowledgements}

This paper developed out of a project, funded by the European Commission, on the health impact of European single market legislation. The authors would like to thank Dr Eric Brunner and Dr Mike Rayner for helpful comments on an earlier draft. Governmental nutrition counterparts in the WHO Member States are thanked for supplying their dietary intake data to WHO.

\section{References}

1 Block G, Patterson B, Subar A. Fruit, vegetables and cancer prevention: a review of the epidemiological literature. Nutr. Cancer 1992; 18: 1-29.

2 Ferro-Luzzi A, Cialfa E, Leclerq C, Toti E. The Mediterranean diet revisited: focus on fruit and vegetables. Int. J. Food Sci. Nutr. 1994; 45: 291-300.

3 Morris DM, Kritchevsky SB, Davis CE. Serum carotenoids and coronary heart disease: the Lipid Research Clinics Coronary Primary Prevention Trial and follow-up study. JAMA 1994; 274: 1439-41.

4 World Health Organization. Diet, Nutrition and the Prevention of Chronic Diseases: Report of WHO Study Group. WHO Technical Series Report No. 797. Geneva: WHO, 1990.

5 Huijbregts P, Feskens E, Rasanen L, et al. Dietary pattern and 20 year mortality in elderly men in Finland, Italy and the Netherlands: longitudinal cohort study. BMJ 1997; 315: 13-7.

6 Findanza F. The Mediterranean diet: keys to contemporary thinking. Proc. Nutr. Soc. 1991; 50: 519-26.

7 Keys A. Seven Countries. A Multivariate Analysis of Death and Coronary Heart Disease. Cambridge, MA: Harvard University Press, 1980.

8 Cannon G, ed. Food, Nutrition and the Prevention of Cancer: A Global Perspective. Washington, DC: World Cancer Research Fund/American Institute for Cancer Research, 1997.

9 Working Group on Diet and Cancer of the Committee on Medical Aspects of Food and Nutrition Policy. Nutritional Aspects of the Development of Cancer. Department of Health: Report on Health and Social Subjects No. 48. London: The Stationery Office, 1998.

10 van't Veer P, Jansen MCJF, Klerk M, Kok FJ. Fruits and vegetables in the prevention of cancer and cardiovascular disease. Public Health Nutr. 2000; 3: 103-7.

11 Ness AR, Powles JW. Fruit and vegetables, and cardiovascular disease: a review. Int. J. Epidemiol. 1997; 26: 1-13.

12 Law MR, Morris JK. By how much does fruit and vegetable consumption reduce the risk of ischaemic heart disease? Eur. J. Clin. Nutr. 1998; 52: 549-56.

13 Parodi PW. The French paradox unmasked: the role of folate. Med. Hypotheses 1997; 49: 313-8.

14 Pietinen P, Rimm EB, Korhonen P et al. Intake of dietary fiber and risk of coronary heart disease in a cohort of Finnish men. The alpha-tocopherol, beta-carotene cancer prevention study. Circulation 1996; 94: 2720-7.

15 Rimm EB, Ascherio A, Giovanucci E, Spiegelman D, Stampfer MJ, Willett WC. Vegetable, fruit and cereal fiber intake and risk of coronary heart disease among men. JAMA 1996; 275 : 447-51.

$16 \mathrm{Hu} \mathrm{FB}$, Stampfer MJ, Manson JE, et al. Frequent nut consumption and risk of coronary heart disease in women: prospective cohort study. BMJ 1998; 317: 1341-5.

17 Key TJ, Fraser GE, Thorogood M, et al. Mortality in vegetarians and non-vegetarians: a collaborative analysis of 8300 deaths among 76,000 men and women in five prospective studies. Public Health Nutr. 1998; 1: 33-41.

18 de Lorgeril M, Salen P, Martin J-L, Monjaud I, Boucher P, 
Mamelle N. Mediterranean dietary pattern in a randomised trial. Arch. Intern. Med. 1998; 158: 1181-7.

19 Schmitt A, Chambolle M, Millstone E, Brunner E, Lobstein T. Nutritional Surveillance in Europe. IPTS/ESTO Task C Project No. 10, 1998.

20 Trichopoulou A, Lagiou P, eds. Methodology for the Exploitation of HBS Food Data and Results on Food Availability in 5 European Countries. DAFNE Report. Luxemburg: European Communities, 1997.

21 Shibata A, Paganini-Hill RK, Henderson R, Henderson BE. Intake of vegetables, fruit, beta-carotene, vitamin $C$, supplements and cancer among the elderly: a prospective study. $\mathrm{Br}$. J. Cancer 1992; 66: 673-9.

22 Negri E, La Vecchia C, Franceschi S, D'Avanzo B, Parazzini F. Vegetable and fruit consumption and cancer risk. Int. J. Cancer 1991; 48: 350-4.

23 Trichopoulos A, Katsouyanni K, Stuver S, et al. Consumption of olive oil and specific food groups in relation to breast cancer risk in Greece. J. Natl. Cancer Inst. 1995; 87: 110-6.

24 Toniolo P, Riboli E, Protta F, Charrel M, Cappa APM. Calorieproviding nutrients and the risk of breast cancer. J. Natl. Cancer Inst. 1989; 81: 278-86.

25 Thun MJ, Calle EE, Namboodiri MM, et al. Risk factors for fatal colon cancer in a large prospective study. J. Natl. Cancer Inst. 1992; 84: 1491-1500.

26 Kneller RW, McLaughlin JK, Bjelke E, et al. A cohort study of stomach cancer in a high-risk American population. Cancer 1991; 68: 672-8.

27 World Health Organization. World Health Statistics Annual 1996. Geneva: WHO, 1998.

28 World Health Organization. World Health Statistics Annual 1994. Geneva: WHO, 1995.

29 EPIC Group of Spain: Agudo A, Amiano P, Barcos A, et al. Dietary intake of vegetables and fruits among adults in five regions of Spain. Eur. J. Clin. Nutr. 1999; 53: 174-80.

30 Aranceta J, Pérez Rodrigo C, Eguileor I, Marzana I, González de Galdeano L, Saenz de Buruaga F. Food consumption patterns in the adult population of the Basque country (EINUT-1). Public Health Nutr. 1998; 1: 185-92.

31 Laitenen S, Rasenen L, Viikari J, Akerblom HK. Diet of Finnish children in relation to the family's socio-economic status. Scand. J. Soc. Med. 1995; 23: 88-94.

32 Bobak M, Hense H-W, Kark J, et al. An ecological study of determinants of coronary heart disease rates: a comparison of Czech, Bavarian and Israeli men. Int. J. Epidemiol. 1999; 28: $437-44$.

33 Kristenson M, Zieden B, Kucinskiene Z, Elinder LS, Bergdahl B, Elwing B, Abaravicius A, Razinkoviene L, Calkauskas H, Olsson AG. Antioxidant state and mortality from coronary heart disease in Lithuanian and Swedish men: concomitant cross sectional study of men aged 50. BMJ 1997; 314: 629-33.

34 Rose G. The Strategy of Preventive Medicine. Oxford: Oxford University Press, 1992.

35 Murray CJL, Lopez A. The Global Burden of Disease. Boston, MA: Harvard University Press, 1996.

36 National Institute of Public Health. Determinants of the Burden of Disease in the EU. Stockholm: National Institute of Public Health, 1997.

37 Piettinen P, Vartiainen E, Seppanen R, Aro A, Puska P. Changes in diet in Finland from 1972 to 1992: impact on coronary heart disease. Prev. Med. 1996; 25: 243-50.
38 Marshall T. Exploring a fiscal food policy: the case of diet and ischaemic heart disease. BMJ 2000; 320: 301-5.

39 World Health Organization. Urban Food and Nutrition Action Plan LVNG 030102 [Online]. Available at http:// www.who.dk/Nutrition/food.htm. Copenhagen: WHO, October 1999

\section{Appendix - Population Attributable Risk Proportion}

For a dichotomous situation, where the population can be divided into those who are exposed and those who are non-exposed, the Attributable Risk is given by:

(incidence in the exposed group)

- (incidence in the non-exposed group),

or

$$
I_{\mathrm{E}}-I_{0},
$$

where the units are of the type cases/population/year.

The formula for the Attributable Risk Proportion is:

$$
\left(I_{\mathrm{E}}-I_{0}\right) / I_{\mathrm{E}}
$$

where the units now cancel out, or (dividing by $I_{0}$ ):

$$
(\mathrm{RR}-1) / \mathrm{RR} \text { or } 1-(1 / \mathrm{RR}) \text {, }
$$

which measures the proportionate change in risk in the exposed group. This would overestimate the change if applied to the whole population. For the latter purpose, it is necessary to use the Population Attributable Risk Proportion:

$\left(I_{\mathrm{E}}-I_{0}\right) /($ incidence rate in the whole population).

In the special case where the exposed and non-exposed groups are equal in size, this is equal to:

$$
\left(I_{\mathrm{E}}-I_{0}\right) /\left(I_{\mathrm{E}}+I_{0}\right),
$$

or (dividing by $I_{0}$ ):

$$
(\mathrm{RR}-1) /(\mathrm{RR}+1) .
$$

For a protective factor, the signs are reversed:

$$
(1-\mathrm{RR}) /(1+\mathrm{RR}) \text {. }
$$

The dichotomous case is shown in Fig. A1 for $\mathrm{RR}=0.5$ and $\mathrm{RR}=0.7$ (first diagram in each case). From the figure, it can easily be seen that the same formula is generalisable to any number of equal-sized groups (tertiles, quartiles, quintiles, etc.) if the trend is monotonic, or even if nonmonotonic but symmetrical. 
Relative risk $=0.5$ :

(a) Dichotomy

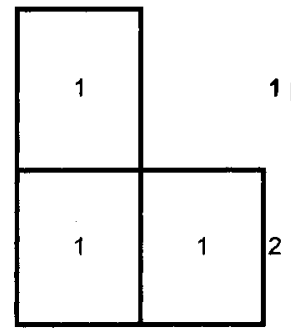

for every 3
1 prevented

$$
\text { i.e. } 1 / 3
$$

(b) Sextiles

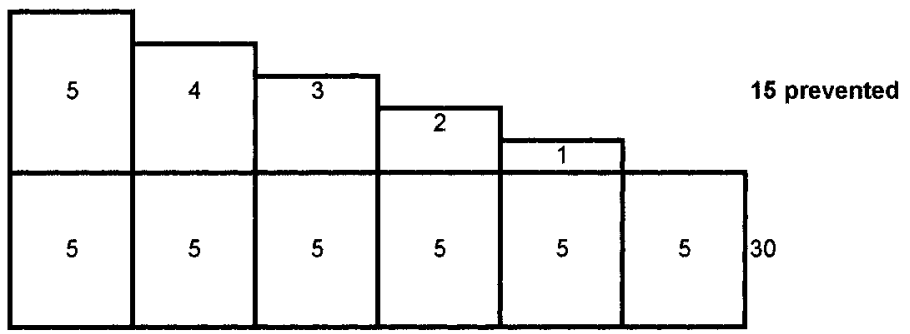

for every 45

i.e. $15 / 45$ or $1 / 3$
Relative risk $=0.7$ :

(a) Dichotomy

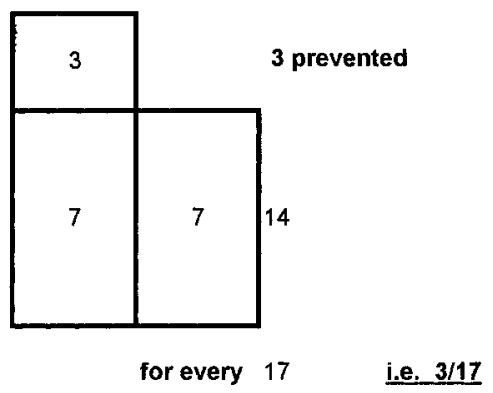

(b) Quartiles

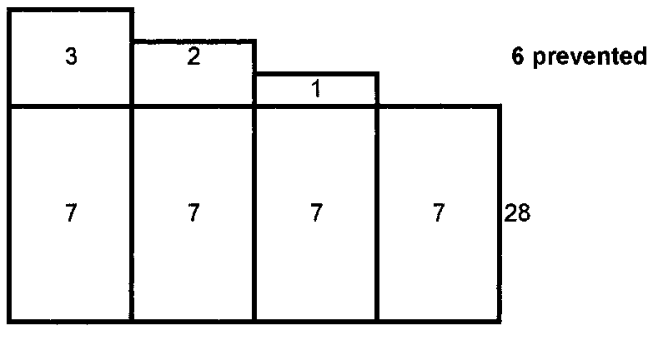

for every 34 i.e. $6 / 34$ or $3 / 17$

Fig. A1 Illustration of the Population Attributable Risk Proportion for a protective factor. The figure illustrates the relationship between the proportion of cases or deaths prevented and the relative risk. Thus, when the relative risk is $0.5,1 / 3$ are prevented; with a relative risk of 0.7 , $3 / 17$ are prevented. These are independent of the number of quantiles 